Карпухина Т. П., Луговской А. В.

\begin{abstract}
Аннотация. Статья посвящена проблеме эволюции островной мифологемы в английской художественной литературе. Цель исследования - определить функциональные особенности островной мифологемы как эволюционирующего феномена в истории английской художественной литературы. Научная новизна исследования заключается в том, что островная мифологема впервые рассматривается как комплексная формально-содержательная единица английской художественной литературы. Полученные результаты показали, что островная мифологема имеет динамическую природу, изменяющуюся под воздействием исторических и художественных условий. На языковом уровне это проявляется в использовании различных лингвистических средств ее репрезентации.
\end{abstract}

\title{
The Evolution of Island Mythologeme in English Fiction
}

\author{
Karpukhina T. P., Lugovskoi A. V.
}

\begin{abstract}
The article addresses the issue of the island mythologeme evolution in English fiction. The purpose of the study is to determine functional features of the island mythologeme as an evolving phenomenon in the history of English fiction. Scientific novelty of the study lies in the fact that the island mythologeme is for the first time considered as a complex formal and content unit of English fiction. The findings have revealed that the island mythologeme has dynamic nature, which changes under historical and artistic conditions. At the language level, this is manifested in the use of various linguistic means of its representation.
\end{abstract}

\section{Введение}

Остров как особый пространственно-временной феномен привлекал внимание людей с начала существования человеческой истории. С течением времени остров перестал восприниматься как чисто географическое образование, став объектом того, что М. Элиаде называет «мистической географией» [25, p. 433], обращающей свое внимание на мифологическую составляющую географических реалий, в нашем случае острова, или части суши, окруженной водой. Остров, а также входящие в его понятийное ядро суша и вода являются неотъемлемыми элементами различных мифологических систем.

Бесспорным является тот факт, что остров оказал определенное влияние на развитие британской культуры и искусства. Поэты, писатели и художники не раз обращались к острову в своих работах. Английская художественная литература представляет собой яркий пример того, как остров доминировал в сознании писателей и поэтов на протяжении веков. «Утопия» Т. Мора, «Буря» У. Шекспира, «Новая Атлантида» Ф. Бэкона, «Робинзон Крузо» Д. Дэфо, «Остров» О. Хаксли, «Повелитель мух» У. Голдинга - это одни из немногих произведений, в которых остров выступает не только пространственным, но и смысловым центром. «Остров, как однажды заметил автор еще одного “островного” романа “Бетонный остров”, Дж. Баллард, - это состояние сознания» (“The island is a state of mind”) [18, p. 29]. Это определило и актуальность настоящего исследования, которая обусловливается недостаточной разработанностью в отечественной лингвистике проблемы эволюции островной мифологемы в английской художественной литературе.

Для достижения цели исследования необходимо решить следующие задачи: 1) определить понятийнотерминологический аппарат исследования, связанный с понятиями «мифологема», «миф» и «архетип»; 2) выявить основные характеристики островной мифологемы в зависимости от конкретной литературной эпохи; 3) проанализировать лингвостилистические средства репрезентации островной мифологемы.

Теоретической базой исследования послужили труды отечественных языковедов, посвященные изучению острова как особой мифопоэтической реалии: А. Н. Афанасьева [3], Н. А. Криничной [7], В. Айрапетяна [2],

Научная статья (original research article) | https://doi.org/10.30853/phil210081

(c) 2021 Авторы. ООО Издательство «Грамота» ( 2021 The Authors. GRAMOTA Publishers). Открытый доступ предоставляется на условиях лицензии СС BY 4.0 (open access article under the CC BY 4.0 license): https://creativecommons.org/licenses/by/4.0/ 
Т. В. Цивьян [14], Л. И. Горницкой и М. Ч. Ларионовой [4]. Кроме того, учитывались работы зарубежных исследователей (Ж. Делеза, Р. Гербера и Дж. Бира) о значимости острова в художественной литературе.

Основными методами исследования являются культурно-исторический метод, интерпретативный анализ и методы лингвистического анализа.

Практическая значимость исследования определяется тем, что результаты работы и фактический материал могут быть использованы при чтении лекций и проведении семинарских занятий по таким дисциплинам, как теория языка, стилистика, интерпретация художественного текста, литературоведение, а также на практических занятиях по английскому языку.

\section{Определение ключевых терминов}

Под мифологемой понимается семантическая единица, представляющая собой отдельный элемент мифа, «заимствование из мифа мотива, темы или ее части и воспроизведение в более поздних фольклорных и литературных произведениях» [6, с. 224]. При этом сам термин «мифологема» может иметь как более узкое, так и более широкое значение. Более узкая трактовка приравнивает мифологему авторскому художественному образу как специфической форме отражения действительности, а также выражения чувств и мыслей творящего субъекта [15, с. 239].

В более широком смысле мифологема представляет собой «знак с определенной мифологической семантикой, несущий в себе комплекс архетипических свойств, мифологических аллюзий» [8, с. 3]. При подобной трактовке мифологема выходит за рамки индивидуального творчества и имеет более тесную связь с мифом и архетипом.

Под мифом зачастую понимают рассказ или повествование о важных для древнего человека природных, социальных, физиологических явлениях [9, с. 559]. Однако существуют и другие трактовки мифа, такие как мифологический космогенез или особое состояние сознания. Мифологический космогенез, как подчеркивает В. П. Руднев, - это «рождение мира из хаоса» [10, с. 170] или то, что позволяет увидеть, каким образом древний человек представлял происхождение и устройство окружающего его мира. В этом смысле О. М. Фрейденберг точно замечает, что миф - это «непосредственная форма познавательного процесса; вскрывая ее, мы вскрываем, как первобытный человек представлял себе объективный мир» [13, с. 34-35].

Миф как особое состояние сознания представляет собой эквивалент «духовной культуры», в терминах которой человеком воспринимается и описывается мир. Это форма общественного сознания, предшествующая исторически таким формам, как религия, искусство, наука, содержащим в себе ряд мифологических моделей [1, с. 222].

Что касается архетипов, они представляют собой «изначальные образы», или «наиболее древние формы представления человечества» [16, с. 106], имеющие универсальный характер и принадлежащие коллективному бессознательному. В этом смысле архетипы исторически предшествуют мифологемам, имеющим определенную привязку к конкретной культуре.

\section{Проблема изучения острова как мифологемы в филологии}

Еще в середине XIX века А.Н. Афанасьев рассматривал остров Буян как важный компонент в пространственно-временной модели мира древних славян. Буян ассоциировался с весной, с зарождением жизни, приносимой с востока ветрами [3, с. 24].

Согласно Н. А. Криничной, остров в различных мифологических системах, в частности в древнерусской, выступает в качестве архетипической модели. «Совокупность островов, крупных и мелких, - это рационализированная трансформация мифического “океанийского острова”, отделенного от греховного и суетного либо неблагополучного и неустроенного мира» [7, с. 854]. Проявления этой архетипической модели - острова блаженных, райские острова, острова мертвых.

В. Айрапетян акцентирует внимание на инакости как идее острова. В противоположность материку остров представляет собой иное, исключительное и особенное место, что делает этот локус идеальным для приключений и чудес. Инакость распространяется не только на остров, но и на его обитателей [2, с. 182]. В этом смысле выбор острова в качестве места действия художественного произведения не случаен, чем подчеркивается «вырванность», «выхваченность» героев из обыденной жизни, «инобытийность» их приключений, разворачиваемых в пределах изолированного от остального мира, замкнутого островного пространства, в котором не действуют общепринятые законы «континента» [5, с. 325].

Т. В. Цивьян определяет остров как мифопоэтическую универсалию и подчеркивает мысль о формировании корпуса островных текстов, объединенных особым сюжетом. Развивая идею В. Айрапетяна об инакости острова, Т. В. Цивьян характеризует остров в терминах обособления, особости, непохожести, индивидуальности и необычности [14, с. 151-155].

Одной из наиболее значимых работ в области исследования острова является монография Л. И. Горницкой и М. Ч. Ларионовой, посвященная проблеме островной мифологемы в русской литературе. Авторы понимают под мифологемой некую структурно-семантическую единицу, инвариант, который отвлечен от конкретных реализаций, но воплощен в художественных образах как его единичных проявлениях [4, с. 13-14]. Исследователи рассматривают мифологему острова в древнерусской литературе, русской литературе XVIII-XIX веков, а также подвергают детальному анализу творчество Гайто Газданова. 
В зарубежной филологии проблемой острова занимались такие исследователи, как G. Deleuze (Ж. Делез), R. Gerber (Р. Гербер), G. Beer (Дж. Бир) и другие.

Ж. Делез пишет, что острова помогают литературе актуализировать и интерпретировать те мифы, которые люди не понимают. Остров выполняет функцию повторного создания (“second creation”), или воссоздания, как, например, в мифе о потопе, когда ковчег приносится волнами на выступающую из воды вершину горы, по сути, на остров [23, p. 17].

Р. Гербер подчеркивает, что образ находящегося за морем острова всегда имел определенный мифологический резонанс. И хотя острова в английской литературе представлены не меньше, чем, возможно, в других литературах, но их влияние оказалось настолько сильным, что произведения на островную тематику сами стали живыми мифами [28, р. 37].

Дж. Бир рассматривает остров как особое пространство, место конфликта человека и природы. Автор отстаивает идею о том, что восприятие острова зависит от позиции наблюдателя. Для стороннего наблюдателя остров - это место уединения либо заточения, но с позиции проживающих на острове людей он является центром и средоточием жизни, торговли, мореходства и т.д. Дж. Бир подчеркивает, что западная художественная литература зачастую обращается к образу острова с позиции внешнего наблюдателя, для которого остров предстает в качестве объекта колонизации, освоения, приобретения. Литературный герой в этом смысле представляет собой образ доминирующего белого человека, чаще всего мужчины, пытающегося завладеть или даже овладеть (в фрейдистском понимании) природой [17].

В английской художественной литературе правомочно вести речь об островной мифологеме как инвариантной концептуальной единице, имеющей в своем содержании определенную универсальную составляющую и ее различные реализации, зависящие от конкретного времени, литературного направления и автора. Культурно-исторические изменения мифологемы можно рассматривать как ее эволюцию, или развитие, связанное с количественно-качественными изменениями определенных социальных комплексов [12, с. 786].

\section{Эволюционные изменения островной мифологемы в английской художественной литературе}

Одной из наиболее ранних репрезентаций островной мифологемы в английской литературе является остров эпохи Возрождения, в частности, в произведении Томаса Мора «Утопия» (1516). В репрезентации мифологемы нашли выражение политические и социальные идеалы того времени. Утопический остров это трансформация древнего мифа об идеальном месте на планете, например Эдема в христианской традиции. Остров в «Утопии» описывается следующим образом:

In this bay there is no great current; the whole coast is, as it were, one continued harbour, which gives all that live in the island great convenience for mutual commerce... On the other side of the island there are likewise many harbours; and the coast is so fortified, both by nature and art [33]. / В этой бухте несильное течение; все побережье - одна сплошная гавань, дающая всем живущим на острове большие удобства для обоюдной торговли... На противоположной стороне острова также много подобных гаваней, и побережье надежно укреплено как природой, так и человеческим трудом (здесь и далее перевод авторов статьи. - Т. К., А. Л.).

В данных строках присутствуют такие компоненты, как удобство (great convenience), условия для торговли (mutual commerce), избыточность (many harbours), защищенность (fortified), а также компромисс между человеком и природой (both by nature and art). Воображение утописта рисует тот остров, на котором в гармонии сосуществуют человек и природа, где первый не испытывает недостатка и чувствует себя защищенным.

Островная тематика была актуальной для английских писателей и мыслителей XVI-XVII веков. К острову обращались У. Шекспир в пьесе «Буря» (1611) и Ф. Бэкон в книге «Новая Атлантида» (1627). Также издавались хроники и книги по истории Англии, в которых давалось обоснование исключительности страны и ее особого исторического пути. Одним из видных представителей того времени был Уильям Кэмден, английский историк и топограф, оставивший после себя наследие в виде трудов “Britannia” (1587), "Annales Rerum Anglicarum et Hibernicarum regnante Elizabetha” (1615) и "Remains of a greater worke concerning Britaine” (1605). В последнем из упомянутых произведений Кэмден называет Британию "the most flourishing and excellent, most renowned and famous isle of the whole world” [Цит. по: 35, p. 124] («самым процветающим и восхитительным, самым прославленным и знаменитым островом во всем мире»). Образные эпитеты и превосходная степень дают общее впечатление о характере содержания всех его работ.

В начале XVIII века островная мифологема предстает не как коллективный идеал, но как индивидуальная Вселенная. Такой остров изображается в романе Д. Дэфо «Робинзон Крузо» (1716) - книге, воплотившей в себе просветительские идеалы того времени. Остров в романе - это своего рода трансформация мифа о творении, где творец-Робинзон не только обживается на изначально кажущемся тюрьмой острове, но проходит эволюционный путь человека от варвара до колонизатора.

Таким выглядит одно из ранних описаний острова Робинзоном:

I was in an island environed every way with the sea: no land to be seen except some rocks... I found also that the island I was in was barren, and, as I saw good reason to believe, uninhabited except by wild beasts [22]... / Я был на острове, окруженном со всех сторон морем: нигде не было видно ни клочка земли, только выступающие скалы... Я также обнаружил, что остров, на котором я оказался, был малоплодороден и, насколько можно было судить, был необитаемым - на нем водились только дикие звери. 
В эпитетах «окруженный» (environed), «малоплодородный» (barren), «необитаемый» (uninhabited) остров изображен изолированным и глухим местом, населенным только дикими животными (wild beasts). Ho просветительский герой не сдается: вооруженный разумом и практическими навыками, Крузо поворачивает неблагоприятные обстоятельства в свою пользу. Через какое-то время это уже другой, измененный герой самодостаточный и самодовольный:

I had nothing to covet, for I had all that I was now capable of enjoying; I was lord of the whole manor; or, if I pleased, I might call myself king or emperor over the whole country which I had possession of [Ibidem]. / Я ни в чем не испытывал нужды, ибо у меня было все, что могло мне доставить радость. Я был лордом целого поместья, или, что мне нравилось еще больще, я мог бы величать себя королем или императором целой страны, которая принадлежала мне.

Градация титулов - лорд, король и император (lord, king, emperor) - это стилистически выраженная метафорическая инициация героя в собственника и колонизатора. Его отношение к острову собственническое. В этом смысле остров становится символом своего времени, отражающим колониальную политику Британии XVII-XVIII веков и тех, кто ее проводил.

В следующем веке островная мифологема находит свое воплощение у английских романтиков. Романтизм абстрагировался от мира реальности и создал свой собственный мир, в котором действуют другие законы, чувства, слова, желания. Как заметила Н. А. Соловьева, «романтизм имеет свои районы бытования, свою географию и образность» $[11$, с. 26].

Остров становится идеальным местом для романтического героя, который не может жить в рамках существующей реальности. Остров - это средство эскапизма для героя, ищущего правду и самого себя. Этим героем поэтому часто является пират либо моряк, что отражено в самих названиях произведений, например «Пират» (“The Pirate”, 1822) у В. Скотта, «Корсар» (“The Corsair”, 1814) у Дж. Байрона.

В романтизме островная мифологема вербализована лексикой, содержащей в себе семантику одиночества (lone, alone, lonely, desolate, solitary, solitude), как в следующих строках «Корсара», где герой счастлив вернуться домой на родной остров: They gain by twilight's hour their lonely isle. To them the very rocks appear to smile [20]. / И в сумерки пред ними остров предстает. И кажется им, что скала улыбку шлет.

Это уже не та благодатная земля, в изображении которой утописты видели идеальный мир, а просветители усматривали материал для деятельности. Чаще всего такой остров будет пустынным, с оголенными отвесными скалами и бесплодными участками, что выражается эпитетами “barren”, “bare”, “rocky”. Например, так изображен остров в поэме Дж. Байрона «Дон Жуан», где героиня, гречанка Гайдэ, смотрит на лежащего без сознания, потерпевшего кораблекрушение героя:

The lady watch'd her lover - and that hour

Of Love's, and Night's, and Ocean's solitude,

O'erflow'd her soul with their united power;

Amidst the barren sand and rocks so rude [19].
Своим желанным леди любовалась

Наедине с любовью, ночью, океаном. Душа ее среди стихий досталась Жестоким берегам и скалам.

Основной прием, используемый в отрывке, - олицетворение. Образы любви, ночи и океана персонифицированы посредством написания их с заглавных букв, использования притяжательного падежа и наделения чувством одиночества, в то время как скалам придается антропоморфное качество грубости, жесткости (rocks so rude). Изображение бесплодного песка и грубых камней усиливает чувства Гайдэ. Помимо пространственных характеристик, в отрывке представлено интересное употребление времени - «час одиночества» (hour of solitude), метонимия, использованная в отношении окружающей героев среды и внутреннего состояния героини. В целом остров изображен как мистическое и мифическое место, где человеческая драма разворачивается на фоне человекообразного окружения.

В XIX веке мифологема острова воплощается в более реалистичном изображении: остров у английских писателей зачастую предстает в образе самой Британии. Авторы критикуют страну и мечтают о более счастливых днях, как, например, в стихотворении У. Морриса «Наступает день» (“Тhe Day Is Coming”, 1884):

And the tale shall be told of a country, a land in the midst of the sea,

And folk shall call it England in the days that are going to...

Men in that time a-coming shall work and have no fear

For to-morrow's lack of earning and the hunger-wolf anear [34]. /

И будет сказ вестись о той стране, что посредине моря,

И люди «Англией» провозвещзют ее вскоре...

Работать будут люди, не бояться,

Что смогут бедными, голодными остаться.

Хотя в данном стихотворении нет конкретного употребления слова «остров», образность острова присутствует в перифразе «земля (страна), окруженная морем» (in the midst of the sea). По сути, автор дает определение острову, образ которого в этом стихотворении символизирует социалистические идеалы, типичные для того периода времени. Автор противопоставляет свое время, в котором царствуют нищета (lack of earning) и голод (hunger-wolf), грядущему времени, где у всех будет работа и не будет страха. В отрывке представлена модальность обещания, выраженная глаголом “shall”, употребленным несколько раз.

Позднее, в 1904 г., Дж. Голсуорси напишет роман «Остров Фарисеев» (“The Island Pharisees”), в котором вынесет свой приговор консервативной и собственнической Англии. Сам заголовок произведения является 
аллюзией к религиозно-общественному движению в Иудее, появившемуся во II в. до н.э. За неоднозначность и внутреннюю противоречивость учение фарисейства было подвергнуто критике. В частности, примеры можно обнаружить в Новом Завете, когда Иисус призывает своих учеников беречься «закваски фарисейской», подразумевая под этим лицемерие. В современном толковании фарисейство понимается как ханжество и лицемерие, как показное служение моральным идеалам, которые на самом деле не имеют нравственных оснований, что следует из самого значения существительного "pharisee” - "someone who pretends to be very religious or moral, but is not” [32, p. 1116] («тот, кто притворяется религиозным или высоконравственным, но таковым не является»).

Дж. Голсуорси обрушил свою критику на фарисейство как общественный феномен. Так, уже в самом названии романа «Остров Фарисеев» присутствует указание на собственную страну, что подтверждается и в авторском предисловии к роману, в котором писатель подчеркивает принадлежность своей нации к фарисеям (we are all Pharisees), а для усиления эффекта использует эмфатическое “do": In the little matter of the title of this book, we are all Pharisees... and we certainly do live upon an Island [27, с. 8]. / А что касается заглавия этой книги - мы все являемся Фарисеями... и мы определенно живем на Острове.

В данном отрывке на себя также обращают внимание написание слова «остров» (an Island) с заглавной буквы и использование его с неопределенным артиклем. С одной стороны, неопределенный артикль указывает на факт проживания на острове вообще, на «некоем» острове. С другой стороны, этот остров имеет конкретного референта (объект действительности), то есть саму Британию.

$\mathrm{C}$ начала XX века в английской художественной литературе усиливается влияние нового художественного направления - модернизма. Отказываясь от восприятия действительности в системе реальных связей, модернизм искал новые художественные формы, в основу которых были положены принципы алогизма, иррационализма, релятивизма, мифологизма, а также изображение окружающего как хаоса и абсурда. Личность в модернизме описывалась отчужденной от социума, погруженной в онтологическую бессмыслицу и не имеющей целенаправленности, то есть на передний план выносились проблемы экзистенциалистского плана [9, с. 567-571].

В модернистской традиции остров подчас становится символом сознательного одиночества человека, одиночества как индивидуального выбора, позволяющего обособиться от окружающих людей и обрести гармонию и покой. Подобное находим у Д. Г. Лоренса. В его романе «Влюбленные женщины» (“Women in Love”, 1920) главный герой размышляет:

If he were on an island, like Alexander Selkirk, with only the creatures and the trees, he would be free and glad, there would be none of this heaviness, this misgiving. He could love the vegetation and be quite happy and unquestioned, by himself [31]. / Если бы он, подобно Александру Селькирку, оказался на необитаемом острове, окружённый зверьми и деревьями, он чувствовал бы себя свободным и радостным, без уныния и недобрых предчувствий. Он смог бы полюбить природу, смог бы стать счастливым и перестать себя терзать.

Посредством использования сослагательного наклонения и сравнения (If he were on an island, like Alexander Selkirk) герой проводит параллель между собой и Александром Селькирком, шотландским моряком, который больше четырех лет прожил на необитаемом острове и впоследствии стал прототипом для Робинзона Крузо. Однако в этом сравнении рождается и парадокс: если для английского моряка пребывание на острове явилось в свое время мучением, то модернистскому герою мукой является пребывание среди себе подобных. Для него остров становится символом свободы и радости.

Сходные модернистские мотивы присутствуют и в творчестве В. Вульф. В одном из ее произведений, «На маяк» (“То the Lighthouse”, 1927), героя будто тянет на клочок земли, на котором он неизбежно найдет свое одиночество:

It was his fate, his peculiarity, whether he wished it or not, to come out thus on a spit of land which the sea is slowly eating away, and there to stand, like a desolate seabird, alone [36, p. 50]. / В том был его удел, его свойство, хотел он того или нет, - сойти на отрезок земли, медленно поглощаемый морем, и одиноко стоять там подобно морской птице.

В отрывке используется антропоморфная метафора моря, медленно поглощающего (пожирающего) полоску земли (the sea is slowly eating away). Сочетание "spit of land” толкуется как “a long narrow area of land that stretches out into the sea or a lake” [32, p. 1438] («длинный узкий отрезок земли, простирающийся в море или в озеро»). Оно необязательно относится к острову, но в самой динамике изображения полоски земли можно уловить ее эфемерность: кажется, что еще мгновение - и море отрежет ее от остальной суши, а потом и вовсе поглотит ее. Этим подчеркивается и мимолетность человеческой жизни, которая в конечном счете размывается и растворяется в небытии. Это экзистенциальный мотив, суть которого сводится к тому, что человек находится один в безбожной Вселенной [21, p. 102]. Несколькими десятилетиями позднее этот мотив появится в романе Дж. Фаулза «Волхв» (“The Magus”, 1965), в разговоре между двумя героями:

"No man is an island."

"Pah. Rubbish. Every one of us is an island. If it were not so we should go mad at once. Between these islands are ships, aeroplanes, telephones, wireless - what you will. But they remain islands. Islands that can sink or disappear for ever" [26, p. 146]. / «Человек - не остров». «Тьфу! Чушь! Каждый из нас - остров. Если бы было по-другому, мы бы сразу же сошли с ума. Эти острова связывают корабли, самолеты, телефоны, радио - да что хочешь! Но они остаются островами. Островами, которые могут утонуть и исчезнуть навсегда».

В отрывке присутствует аллюзия к работе Дж. Донна «Посвящения в связи с наступающими событиями» (“Devotions upon Emergent Occasions”, 1624), в которой английский поэт и проповедник писал, что ни один человек не является островом, но частью континента: No man is an Iland, entire of itselfe; every man is a peece 
of the Continent [24, p. 126]... В представлении Дж. Донна, континент - это общность людей, связанных верой. Четыре столетия спустя индивидуализм и эгоизм современного человека не нашли места для Бога - каждый стал островом в безбожном океане людей. При этом парадокс и одновременно несчастье такого человека заключены в том, что кажущийся уровень развития коммуникации и соответствующих ее средств не смог обеспечить должной связи и сплоченности; одиночество человека - не материальная, но экзистенциальная характеристика.

В двадцатом веке человечество потеряло надежду, не найдя рая на земле: утопические мечты превратились в антиутопические кошмары, подобно тем, что представлены в двух островных романах: «Повелитель мух» (“Lord of the Flies”, 1954) У. Голдинга и «Остров» (“Island”, 1962) О. Хаксли. Обе книги объединяет сюжетное развитие: начинаясь с утопического оптимизма, они заканчиваются хаосом и разрушением, казалось бы, устойчивого социального конструкта. В конце романа У. Голдинга дети пребывают в варварском состоянии на «горящих останках острова» (“the burning wreckage of the island” [29, с. 224]), а в книге О. Хаксли идиллия острова Палы разрушена пришедшей диктатурой: The work of a hundred years destroyed in a single night [30, p. 285]. / Старания сотен лет, уничтоженные за одну ночь.

Оба произведения - это притчи, аллегории, где остров представляет собой кумулятивный опыт предшествующей образности: миф о творении превращается в миф о разрушении, в апокалиптические ожидания человечества своей судьбы. Эволюция ведет не только к повышению уровня организации системы, но и к его понижению, регрессу [12, с. 786]. Мифологема острова в XX веке и после воплощена в литературе как компонент деструктивного начала мира, дезориентированного и разобщенного.

\section{Заключение}

Результаты исследования позволяют сформулировать следующие выводы.

1. Мифологема как объект изучения филологии может пониматься в узком и широком смыслах. В более узком смысле мифологема представляет собой авторский художественный образ. В более широком смысле мифологема относится к универсальным феноменам, включающим в себя архетипические и мифологические характеристики универсальной человеческой культуры.

2. Конкретные воплощения островной мифологемы имеют характеристики определенной художественной эпохи. Например, в эпоху Возрождения островная мифологема служила утопическим идеалом. В эпоху Просвещения остров использовался средством создания индивидуальной реальности колонизатора посредством прагматизма и разума. В романтический период, как и в модернизме, островная мифологема служила средством ухода героев от реальности и отражения их внутреннего состояния. В эпоху реализма остров выполнял функцию реалистичного и критического изображения самой Британии. В середине XX века островная мифологема воплощает в себе невозможность достижения утопических идеалов.

3. На лингвостилистическом уровне островная мифологема вербализована эпитетами, метафорами, аллюзиями, символами, аллегориями и другими стилистическими средствами.

В качестве перспективы дальнейшего исследования необходимо проанализировать больший объем художественных текстов, что позволит дать более глубокое понимание функционирования островной мифологемы в английской художественной литературе и культуре в целом, а также поспособствует определению характера связей между ее внутренней семантикой и формами лингвистического воплощения.

\section{Список источников}

1. Аверинцев С. С., Эпштейн М. М. Мифы // Литературный энциклопедический словарь / общ. ред. В. М. Кожевникова, П. А. Николаева. М.: Советская энциклопедия, 1987. С. 222-225.

2. Айрапетян В. Толкуя слово: опыт герменевтики по-русски. М.: Языки славянской культуры, 2001. 484 с.

3. Афанасьев А. Н. Языческие предания об острове-Буяне // Происхождение мифа: статьи по фольклору, этнографии и мифологии. М.: Индрик, 1996. С. 16-32.

4. Горницкая Л. И., Ларионова М. Ч. Место, которого нет... Острова в русской литературе. Ростов-на-Дону: ЮНЦ РАН, 2013. 226 с.

5. Карпухина Т. П. Морфемный повтор в художественном тексте в свете общеэстетической теории игры: монография. Хабаровск: ДВГГУ, 2006. 392 с.

6. Козлов А. С. Мифема, мифологема // Современное зарубежное литературоведение (страны Западной Европы и США): концепции, школы, термины: энциклопедический справочник / под ред. И. П. Ильина, Е. А. Цургановой. М.: Интрада - ИНИОН, 1999. С. 224-225.

7. Криничная Н. А. Русская мифология: мир образов фольклора. М.: Академический Проект; Гаудеамус, 2004. $1008 \mathrm{c}$.

8. Кузнецова А. И. Пространственные мифологемы в творчестве У. Голдинга: автореф. дисс. ... к. филол. н. M., 2004. 20 c.

9. Литературная энциклопедия терминов и понятий / под ред. А. Н. Николюкина. М.: Интелвак, 2001. 1600 с.

10. Руднев В. П. Словарь культуры ХХ века. М.: Аграф, 1999. 384 с.

11. Соловьева Н. А. Типы художественного сознания в XIX веке // История зарубежной литературы XIX века: учеб. для вузов / общ. ред. Н. А. Соловьевой. М.: Академия, 2000. С. 21-49. 
12. Философский энциклопедический словарь / под ред. Л. Ф. Ильичева, П. Н. Федосеева, С. М. Ковалева, В. Г. Панова. М.: Сов. энциклопедия, 1983. 840 с.

13. Фрейденберг О. М. Миф и литература древности. Изд-е 2-е. М.: Восточная литература, 1998. 800 с.

14. Цивьян Т. В. Остров, островное сознание, островной сюжет // Язык: тема и вариации. Избранное: в 2-х кн. М.: Наука, 2008. Кн. 2. Античность. Язык. Знак. Миф и фольклор. Поэтика. С. 151-160.

15. Эстетика: словарь / общ. ред. А. А. Беляева. М.: Политиздат, 1989. 447 с.

16. Юнг К. Г. Собрание сочинений. Психология бессознательного / пер. с нем. М.: Канон, 1994. 320 с.

17. Beer G. Island bounds // Islands in history and representation / ed. by R. Edmond, V. Smith. L.: Routledge, 2003. P. 32-42.

18. Burns A., Sugnet Ch. The Imagination on Trial: British and American Writers Discuss Their Working Methods. L.: Allison and Busby, 1981. 170 p.

19. Byron G. Don Juan [Электронный ресурc]. URL: https://www.gutenberg.org/files/21700/21700-h/21700-h.htm (дата обращения: 20.01.2021).

20. Byron G. The Corsair [Электронный ресурc]. URL: https://www.gutenberg.org/files/21811/21811-h/21811-h.htm (дата обращения: 20.01.2021).

21. Current Literary Terms: A Concise Dictionary / ed. by Arthur Finley Scott. L.: The Macmillan Press, Ltd., 1979. 324 p.

22. Defoe D. The Life and Adventures of Robinson Crusoe [Электронный ресурc]. URL: http://www.gutenberg.org/ files/521/521-h/521-h.htm (дата обращения: 18.01.2021).

23. Deleuze G. Desert Islands: And Other Texts. P.: Semiotext(e), 2004. 323 p.

24. Donne J. Selected prose. L.: Penguin Classics, 1987. 352 p.

25. Eliade M. Patterns of Comparative Religion. N. Y.: New American Library, 1963. 484 p.

26. Fowles J. The Magus. L.: Vintage, 2004. 656 p.

27. Galsworthy J. The Island Pharisees = Остров Фарисеев: книга для чтения на английском языке. СПб.: КАРО, 2007. 384 c.

28. Gerber R. The English Island Myth // The Critical Quarterly. 1959. Vol. 1. № 1. P. 36-43.

29. Golding W. Lord of the Flies // Голдинг У. Повелитель мух. Пирамида. Чрезвычайный посол: сборник / на англ. яз.; сост. М. М. Зинде. М.: Прогресс, 1982. С. 37-297.

30. Huxley A. Island. L.: Vintage Books, 2005. 286 p.

31. Lawrence D. H. Women in Love [Электронный ресурс]. URL: https://www.gutenberg.org/files/4240/4240-h/ 4240-h.htm (дата обращения: 23.01.2021).

32. Macmillan English Dictionary for Advanced Learners / ed. by M. Rundell. 2nd ed. Oxford: Macmillan Publishers, Limited, 2007. 1750 p.

33. More Th. Utopia [Электронный ресурс]. URL: http://www.gutenberg.org/ebooks/2130 (дата обращения: 24.01.2021).

34. Morris Ch. The Day Is Coming [Электронный ресурc]. URL: https://www.gutenberg.org/files/3170/3170-h/3170-h.htm (дата обращения: 23.01.2021).

35. Sanders A. The Short Oxford History of English Literature. 3rd ed. Oxford: Oxford UP, 2004. 756 p.

36. Woolf V. To the Lighthouse. L.: Penguin Books, 1992. 268 p.

\section{Информация об авторах | Author information}

RU Карпухина Тамара Петровна ${ }^{1}$, д. филол. н., доц. Луговской Александр Витальевич ${ }^{2}$

1,2 Тихоокеанский государственный университет, г. Хабаровск

EN Karpukhina Tamara Petrovna ${ }^{1}, \mathrm{Dr}$

1,2 Pacific National University, Khabarovsk

${ }^{1}$ tkarpukhina1@mail.ru, 2lugovskoy_2004@mail.ru

\section{Информация о статье | About this article}

Дата поступления рукописи (received): 27.01.2021; опубликовано (published): 09.04.2021.

Ключевые слова (keywords): островная мифологема; английская художественная литература; формальносодержательная единица; лингвистические средства репрезентации; island mythologeme; English fiction; formal and content unit; linguistic means of representation. 